\title{
A UNIVERSALIDADE DOS DIREITOS HUMANOS DIANTE DA DIVERSIDADE CULTURAL: A POSSÍVEL VIA DA INTERCULTURALIDADE
}

\section{Bruna Hoisler Sallet ${ }^{*}$}

\section{RESUMO:}

$\mathrm{O}$ artigo tem por objetivo estudar a universalidade dos direitos humanos, assim como seus alcances e limites em sociedades marcadas pela diversidade cultural. Para tanto, questiona em que medida a ideia de interculturalidade pode representar a combinação entre o respeito à diversidade cultural e o universalismo dos direitos humanos. Isso porque, não raras vezes, o discurso universal dos direitos humanos é utilizado como justificativa para práticas imperialistas sobre aqueles que não conjugam do paradigma liberal-individualista da modernidade. Por fim, assinala que toda comunidade tem princípios éticos comuns, os quais devem ser interpretados de acordo com a diversidade cultural.

Palavras-chave: Direitos Humanos; Diversidade Cultural; Universalismo; Relativismo; Interculturalidade.

\section{THE UNIVERSALITY OF HUMAN RIGHTS IN FACE OF CULTURAL DIVERSITY: THE WAY OF INTERCULTURALITY}

\begin{abstract}
:
The article aims to study the universality of human rights, as well as their reach and limits in societies marked by cultural diversity. To this end, it questions thow the idea of interculturality can represent the combination of respect for cultural diversity and universalism of human rights. This is because, not infrequently, the universal discourse of human rights is used as a justification for imperialist practices on those that do not match the liberal-individualist paradigm of modernity. Finally, it indicates that every community has common ethical principles, which must be interpreted according to cultural diversity.
\end{abstract}

Keywords: Human Rights; Cultural Diversity; Universalism; Relativism; Interculturality.

\section{INTRODUÇÃO}

O presente artigo busca estudar a universalidade dos direitos humanos, seus fundamentos, bem como seus alcances e limites, em sociedades marcadas pela diversidade cultural. Para tanto, questiona em que medida a ideia de interculturalidade pode representar a conjugação entre o respeito à diversidade cultural e o universalismo dos direitos humanos.

\footnotetext{
* Mestranda em Direito, área de concentração em Direitos Sociais, no Programa de Pós-Graduação em Direito na Universidade Federal de Pelotas (PPGD/UFPel). Bolsista da Coordenação de Aperfeiçoamento de Pessoal de Nível Superior (CAPES). Graduada em Direito pela mesma instituição, com mobilidade acadêmica internacional na Faculdade de Direito da Universidade de Coimbra. Endereço eletrônico: bhsallet@ gmail.com
} 
Isso porque, não raras vezes, o discurso universal dos direitos humanos foi utilizado como justificativa para práticas imperialistas sobre aqueles que não conjugam do paradigma liberalindividualista dessas declarações modernas.

Em um primeiro momento, discorre-se sobre a proposta historicista de direitos humanos de Norberto Bobbio, indicando as etapas na história das declarações de direitos que, em suma, passou da universalidade abstrata dos direitos naturais, transfigurando-se na particularidade concreta dos direitos positivos, e terminou na universalidade não mais abstrata, mas também ela concreta, dos direitos positivos universais. Além disso, aponta-se a interpretação de Bobbio acerca da necessidade de superação da questão filosófica do fundamento dos direitos humanos como maneira de dar enfoque na busca dos meios necessários para garantir-lhes efetividade.

Em um segundo momento, discorre-se sobre a interpretação de Vicente Barretto que, diferentemente de Bobbio, vê importância crucial no debate acerca dos fundamentos dos direitos humanos, afinal, para o autor, a partir de um fundamento universal, o problema central da efetivação dos direitos humanos poderia ter alguma solução. Ainda, coloca-se que, segundo Barretto, a universalidade dos direitos humanos não obsta o respeito a outras culturas, uma vez que vê saída no diálogo intercultural para o problema levantado pelos relativistas.

No terceiro momento, problematiza-se a questão da desconfiança para com o discurso ocidental e imperialista dos direitos humanos. Aponta-se a possibilidade de associação entre a universalização dos direitos humanos e o respeito à autonomia de outras culturas, pois, segundo o referencial teórico utilizado, em todos os povos pode ser encontrado um mínimo comum. Acrescenta-se a importância da interculturalidade ao reconhecer o pluralismo jurídico de tipo comunitário- participativo como mecanismo de diálogo intercultural, o qual busca a efetivação de direitos humanos considerando realidades culturais distintas e garantindo voz aos indivíduos e grupos comumente marginalizados, construindo, portanto, uma nova cultura de direitos humanos.

Sendo assim, a pesquisa usa como método de abordagem o hipotético- dedutivo, uma vez que parte de referenciais teóricos sobre a temática, alcançando, finalmente, um caso prático específico sobre a questão, tendo como hipótese a possibilidade da interculturalidade como alternativa para a combinação entre o universalismo dos direitos humanos e o respeito às diferentes culturas que não as ocidentais. Como técnica de pesquisa, é utilizada a revisão bibliográfica, em livros e artigos científico sobre a temática, bem como a documental, 
representada pela análise da sentença $\mathrm{n}^{\circ}$ 1422/2012, do Tribunal Constitucional Plurinacional boliviano.

Por fim, assinala-se que toda comunidade tem princípios éticos comuns a toda humanidade, os quais podem ser traduzidos na dignidade humana. Sendo assim, a universalização dos direitos humanos se torna possível sem que para isso signifique uma imposição hegemônica de uma cultura sobre a outra. O diálogo intercultural, portanto, permite um encontro que possibilita a aceitação do diferente como uma oportunidade de enriquecimento e transformação de ambas as partes, apresentando- se, portanto, como um projeto ético-político libertador.

\section{A PROPOSTA HISTORICISTA DE DIREITOS HUMANOS E A BUSCA DE SUA EFETIVIDADE A PARTIR DA SUPERAÇÃO DO PROBLEMA DOS SEUS FUNDAMENTOS}

A construção histórica dos direitos humanos, compreendendo sua busca pelo reconhecimento, efetivação, implantação e manutenção, perpassou por diversos contextos. Segundo Bobbio (2004, p. 18), a história das declarações de direitos é distinguida, pelo menos, por três fases.

A primeira etapa pode ser identificada nas obras filosóficas que sustentavam que o homem possuía direitos considerados naturais. Os direitos do homem eram pura e simplesmente a expressão de um pensamento individual: são universais em relação ao conteúdo, mas são limitados em relação à eficácia. Depois, quando as teorias filosóficas foram reconhecidas por um legislador, como ocorreu através da Declaração de Direito dos Estados Norte-americanos e com a Declaração Francesa, estabeleceu-se a formação de um sistema de valores e a instituição de um autêntico sistema de direitos positivos ou efetivos (BOBBIO, 2008, p. 18-19).

A segunda fase, portanto, representa a efetivação dos direitos através da sua positivação, possuindo validade dentro de um determinado Estado, que não mais absoluto e sim limitado. Ou seja, inicia com a passagem da teoria à prática, do direito somente pensado para o direito realizado. Nessa passagem, a afirmação dos direitos do homem ganha em concreticidade, mas perde em universalidade. Os direitos são protegidos, mas valem somente no âmbito do Estado que os reconhece. Assim, não são mais direitos do homem e sim do cidadão (BOBBIO, 2008, p. 19). 
A partir da Declaração Universal dos Direitos Humanos, de 1948, tem início a terceira fase, na qual a afirmação dos direitos é, ao mesmo tempo, positiva e universal. Esta última característica pode ser entendida no sentido de que os destinatários dos princípios nela contidos não são mais apenas os cidadãos deste ou daquele Estado, mas todos os homens. Assim, os direitos do cidadão se transformam em direitos do homem (BOBBIO, 2008, p. 19).

Portanto, observa-se um movimento dialético, que começa pela universalidade abstrata dos direitos naturais, transfigura-se na particularidade concreta dos direitos positivos, e termina na universalidade não mais abstrata, mas também ela concreta, dos direitos positivos universais.

Com relação ao conteúdo, a Declaração não é definitiva. Isso porque, conforme explanado acima, os direitos do homem são direitos históricos, que emergem gradualmente das lutas emancipatórias da humanidade diante das suas condições de vida em um dado contexto histórico. Diante disso, a comunidade internacional precisa continuamente aperfeiçoar, articular, especificar e atualizar o conteúdo da Declaração Universal, assim como fornecer garantias válidas para aqueles direitos.

Segundo Bobbio (2004, p. 21), um dos fenômenos mais interessantes no problema da garantia dos direitos do homem é aquele relacionado ao processo de descolonização. $\mathrm{Na}$ Declaração sobre a Concessão da Independência aos Países e Povos Coloniais, aprovada em 1960, tem-se a referência genérica aos direitos do homem globalmente considerados, mas tem-se também a afirmação de que a sujeição dos povos ao domínio estrangeiro é uma negação dos direitos fundamentais do homem.

A primeira afirmação refere-se à pessoa individual enquanto a segunda a todo um povo. Ou seja, uma alcança a não-discriminação individual e a outra prossegue até a autonomia coletiva. Portanto, torna-se evidente a tomada de consciência dos novos valores e, consequentemente, da exigência de afirmar direitos fundamentais dos povos que não estavam necessariamente incluídos anteriormente. Sendo assim, desenham-se novos direitos de grupos humanos, povos e nações para além dos direitos do homem como indivíduo.

Ocorre que embora a evidente evolução na questão dos direitos humanos, especialmente diante das inúmeras declarações de direitos aprovadas, eles permanecem sendo constantemente violados. Sobre o problema dos direitos humanos, Bobbio alertou: 
O problema que temos diante de nós não é filosófico, mas jurídico e, num sentido mais amplo, político. Não se trata de saber quais e quantos são esses direitos, qual é sua natureza e seu fundamento, se são direitos naturais ou históricos, absolutos ou relativos, mas sim qual é o modo mais seguro para garanti-los, para impedir que, apesar das declarações solenes, sejam continuamente violados. (BOBBIO, 2008, p. 17).

Bobbio aponta que mais importante que permanecer na infindável discussão acerca dos fundamentos dos Direitos Humanos é partir para efetivação deles. Assim, o autor discorre que a questão dos fundamentos dos direitos humanos deve ser superada, considerando que a Declaração de Direitos Humanos de 1948 instituiu um sistema de valores que pode ser considerado universal de fato. A partir dela é possível dizer que a humanidade compartilha alguns valores comuns.

A Declaração Universal representa um fato novo na história, na medida em que, pela primeira vez, um sistema de princípios fundamentais da conduta humana foi livre e expressamente aceito, através de seus respectivos governos, pela maioria dos homens que vive na Terra. Com essa declaração, um sistema de valores é - pela primeira vez na história — universal, não em princípio, mas de fato, na medida em que o consenso sobre sua validade e sua capacidade para reger os destinos da comunidade futura de todos os homens foi explicitamente declarado. (BOBBIO, 2008, p. 18).

Portanto, ao considerar esses direitos como valores, os quais não se justificam, mas se assumem, Bobbio defende a ideia de que se ignore o problema da fundamentação e se parta para a efetiva proteção dos direitos humanos. Entretanto, importante dizer que, quando o autor aponta como problema mais urgente o da garantia e não do fundamento, não quer dizer que considera o problema do fundamento como inexistente, mas sim como, de certa forma, resolvido. Ou seja, considera problema cuja solução já não devemos mais nos preocupar, afinal, teve sua solução no consenso existente na Declaração Universal (BOBBIO, 2008, p. 17).

Bobbio adota, assim, uma concepção historicista dos direitos humanos, afastando o conteúdo ético e centrando-se no consenso da comunidade internacional acerca dos direitos elencados na Declaração Universal como critério de legitimidade. Com essa postura, Bobbio deixa de justificar o porquê da escolha de um e não de outro direito.

A positivação dos direitos humanos não explica, por exemplo, o porquê da definição e da escolha de determinados direitos e não de outros; não explica por que diferentes sociedades ocidentais, com história política e econômica diversas, adotaram, em regra, uma mesma orientação valorativa na definição 
de suas cartas políticas de direitos humanos; não explica ainda o fato de sociedades não ocidentais concordarem, ao menos em parte, com um conjunto desses direitos mesmo antes das revoluções do século XVIII. (LUCAS, 2009, p. 129).

Ou seja, o fato histórico do reconhecimento jurídico dos direitos humanos é de suma importância, entretanto, não nega a necessidade de uma justificação para as declarações modernas de direitos humanos, conforme dispõe o último autor. Nesse sentido, existem diversos entendimentos referentes à questão da justificação e fundamentos dos direitos humanos.

\section{A RETOMADA DO PROBLEMA DOS FUNDAMENTOS DOS DIREITOS HUMANOS COMO INDISPENSÁVEL DE SUA PROTEÇÃO}

Diante da posição historicista de Bobbio, importante apontar a interpretação que defende a natureza ética no fundamento dos direitos humanos, sendo, por isso, chamados de direitos morais. Portanto, seriam morais porque refletem as exigências éticas decorrentes da ideia de dignidade humana.

Nesse ponto, importante trazer o pensamento de Vicente Barretto, o qual discorre que, embora seja verdadeira a assertiva de Bobbio sobre o problema básico dos direitos humanos residir na efetiva garantia deles, não concorda que, para tanto, a questão da fundamentação dos direitos humanos deva ser considerada superada. Isso porque há casos em que a justificação e a fundamentação dos direitos é etapa indispensável e indissociável da sua proteção (BARRETTO, 2010, p. 202).

Um sistema positivo de direitos separado de valores morais, que procure a garantia dos direitos humanos simplesmente na lei de um país, não traz a proteção necessária para as diversas violações de direitos. Ao contrário, pode servir, inclusive, para justificar violações. Diante disso, propõe-se um direito que tenha presente componentes morais, sociais e políticos, que salvaguardam as condições essenciais mínimas, constitutivas da dignidade da pessoa humana.

Esse entendimento dos direitos humanos, como valores substanciais $\mathrm{e}$ universais permite que se estabeleça a ligação, tantas vezes negada pelas diferentes formas de positivismo jurídico, entre a ordem moral, constituída por agente livres e iguais, e a ordem jurídica própria da sociedade e do Estado. Com isto os direitos humanos adquirem o status de direitos morais, mas que 
perpassam os ordenamentos jurídicos nacionais e permitem que sejam considerados como a espinha dorsal jurídico-institucional da sociedade democrática. (CULLETON; BRAGATO; FARJADO, 2009, p. 262).

Para tanto, segundo Barretto (2010, p. 251), é necessária a construção de uma teoria justificadora dos direitos humanos que possa fundamentá-los. Além disso, discorre que essa fundamentação supõe a recuperação e a superação da dicotomia universalismo e relativismo. Assim, para que se situem os direitos humanos no contexto de uma sociedade multicultural, é necessário passar pela elaboração teórica dos fundamentos dos direitos humanos atentando-se às peculiaridades empíricas encontradas nas diferentes culturas (BARRETTO, 2010, p. 247).

Segundo os relativistas, é impossível existir um catálogo de direitos humanos uniforme para regular todos os povos do planeta, devido à variabilidade dos costumes e à pluralidade do Direito, "pois aquilo que deve ser atribuído a cada um, em um dado grupo social, depende das circunstâncias, da massa de bens para distribuir, do estado da civilização e da cultura" (CULLETON; BRAGATO; FAJARDO, 2009, p. 236). Dessa forma, seria impossível, para os relativistas, satisfazer de forma igual as exigências de bem-estar de todos os seres humanos, já que existe na humanidade uma variedade de valores, hábitos e práticas sociais (BARRETTO, 2010, p. 251).

Assim, o argumento comumente aceito contra a universalidade dos direitos humanos, elaborado por essas correntes relativistas, socorre-se de uma leitura redutora do multiculturalismo encontrado na humanidade (BARRETTO, 2010, p. 251). Entretanto, a situação pode ser lida de forma não-reducionista, especialmente ao observar que nas culturas locais também se encontra uma enorme gama de interpretações da própria tradição e das práticas culturais.

Os movimentos de afirmação dos direitos humanos efetuados pelos excluídos dentro do seu próprio grupo social evidenciam como em situações excludentes o recurso aos valores expressos pelos direitos humanos constituem um mínimo moral e jurídico comum a todas as sociedades. Essa fundamentação crítica ou moral poderá ser resumida na ideia de dignidade humana. A manutenção da dignidade humana constitui, assim, o cerne dos direitos humanos, pois através deles serão asseguradas as múltiplas dimensões da vida humana (BARRETTO, 2010, p. 272).

Portanto, embora os relativistas rejeitem uma espécie de imperialismo ético no qual não é possível existir uma moral superior (CULLETON; BRAGATO; FAJARDO, 2009), é importante esclarecer que, na universalização dos direitos humanos, não se pretende 
uniformizar os padrões culturais no mundo, nem impor um padrão moral de uma nação sobre a outra. A ideia central é sedimentar os laços de solidariedade por meio de um mínimo universal entre as características comuns nos seres humanos e que devem ser respeitadas independentemente do espaço cultural em que estejam incorporadas (MAZZA; COSTA, 2016, p. 402).

Todas as culturas possuem a noção de direitos humanos, seja a islâmica, a budista, ou qualquer outra não ocidental. Tais culturas possuem diferenças entre si, entretanto, tais diferenças não são obstáculos à universalização desses direitos. Nesse sentido, Culleton, Bragato e Farjado (2009, p. 241) afirmam que a aproximação de valores de outras culturas, que não a cultura ocidental, com valores expressos nos direitos humanos, demonstra que eles podem ser universalizáveis, desde que respeitadas às especificidades de cada cultura.

\section{A SAÍDA PELA INTERCULTURALIDADE: A UNIVERSALIDADE DOS DIREITOS HUMANOS COM O RESPEITO À DIVERSIDADE CULTURAL}

A sociedade democrática é configurada pela multiplicidade de valores culturais, com diferentes compromissos morais, concepções sobre a vida digna e visões religiosas do mundo. Segundo André de Carvalho Ramos (2005, p. 182), as maiores críticas ao universalismo dizem respeito, inicialmente, ao fato de que, para muitos, trata-se de uma forma de colonialismo, sendo a proteção de direitos humanos uma indisfarçável ingerência estrangeira nos assuntos internos, cuja consequência seria a imposição de valores com o consequente sacrifício da diversidade cultural.

$\mathrm{Na}$ verdade, não se deixa de ver os interesses das grandes potências por trás do discurso dos direitos humanos, mesmo porque, guerras e ataques, declarados em sua defesa, continuaram se repetindo, mesmo no século XXI. Nesse sentido, no que diz respeito aos direitos humanos logo após a Segunda Grande Guerra, importante a observação de Santos (1997, p. 112), já que "as políticas de direitos humanos estiveram em geral ao serviço dos interesses econômicos e geopolíticos dos Estados capitalistas hegemônicos".

Bragato (2010, p. 105), enfatiza a existência de um discurso hegemônico de direitos humanos que não ultrapassa as fronteiras do Ocidente. Menciona que se trata de um discurso cujo privilégio da enunciação é, justamente, ocidental, pautado em direitos humanos que são produto das circunstâncias que se consolidaram na Europa e nos Estados Unidos em um dado contexto. A consequência desse discurso é, segundo a autora, a sugestão de que, em relação 
aos direitos humanos, "a história, os valores e as práticas de outras culturas não tiveram, e continuam não tendo, qualquer relevância para a construção desta ideia”.

Denota-se, portanto, que a própria inversão ideológica dos direitos humanos, que os torna a própria causa de sua destruição quando seus titulares são aqueles que se opõem à lógica liberal-burguesa, mostra em que medida a concepção e a valoração da cultura representam um papel importante na forma como esses direitos podem ser protegidos e efetivados (BRAGATO, 2017, p. 42).

Diante disso, perdura a desconfiança que persegue a ideia dos direitos humanos e obstaculiza suas possibilidades de validez universal. Essa desconfiança relaciona-se com a história dos direitos humanos e sua ligação aos pressupostos liberais das Revoluções Americana e Francesa do século XVIII - liberdade, igualdade e segurança -, os quais resultaram em direitos ao homem burguês, branco e ocidental (BRAGATO, 2009, p. 82).

Por outro lado, ainda que tenham se consagrado como direitos burgueses, é inegável que se tem ampliado seu espectro de incidência e alcançado, não apenas o homem burguês, senão um universo cada vez mais amplo de seres humanos. Sobretudo a partir do final do século XIX, quando foram, paulatinamente, se incorporando aos sistemas constitucionais de diversos países, o reconhecimento dos direitos sociais - saúde, educação, regulamentação das relações de trabalho - implicando no impacto da cidadania sobre outras classes sociais, que não a burguesia (BRAGATO, 2009, p. 82).

Portanto, trata-se de uma crítica pertinente para sua época, mas que se analisada no atual contexto não traduz o propósito e o alcance dos direitos humanos, que é o seu reconhecimento baseado na dignidade humana. Tal conceito refuta a imagem egoísta do ser humano e implica um universo de seres humanos mais amplo que o do homem burguês, branco e ocidental (BRAGATO, 2009, p. 83).

Por estas razões que, mesmo dentro da característica da universalidade, a formulação geral do conceito de direitos humanos deve trazer um diálogo entre as culturas. Isso porque, se deve ter em mente que, o fato de outras culturas não possuírem uma noção idêntica de direitos humanos, tal como a do Ocidente, "não significa que não tenham equivalentes que traduzam as exigências de respeito e de promoção de uma vida digna, da mesma forma que o fazem os direitos humanos" (BRAGATO, 2010, p. 114).

Considerando, portanto, que toda comunidade tem princípios éticos comuns a toda humanidade e que são transcendentes às especificidades de cada cultura local, tem-se a ideia do mínimo moral, compatível com muitas culturas e com a diversidade moral, desde que se 
interpretem os direitos humanos no contexto da diversidade (CULLETON; BRAGATO; FARJADO, 2009, p. 241-242). Diante disso, a

universalização dos direitos humanos se torna possível sem que para isso signifique uma imposição hegemônica de uma cultura sobre a outra.

Assim, urge uma releitura sobre a concepção de direitos humanos, a fim de que o seu discurso não traga uma ideia hegemônica, especialmente diante da existência das mais diversas culturas no mundo. Portanto, a interculturalidade pode ser um caminho ao proporcionar:

Inclusão, de encontro qualitativo e solidário com o outro diferente, um encontro que deve possibilitar a aceitação do diferente como uma oportunidade de enriquecimento e transformação de ambas as partes. Assim, a via intercultural se coloca como crítica tanto à cultura hegemônica excludente quanto ao multiculturalismo, e se apresenta como um projeto ético-político libertador, renovador e aberto, cujo objetivo inconteste é a busca pela convivência - entre indivíduos e povos ou nações - pacífica. (BRAGATO; BARRETTO; FILHO, 2017, p. 54).

Diante do exposto, vale agregar que, para Wolkmer (2006, p. 120), a interculturalidade permite "o reconhecimento de outra cultura jurídica, marcada pelo pluralismo de tipo comunitário-participativo e pela legitimidade construída através das práticas internalizadas de sujeitos sociais", o que é fundamental para que surja uma nova cultura de direitos humanos, que possa enfrentar a tradição moderna e dar voz aos indivíduos e grupos marginalizados da América Latina.

O pluralismo jurídico preconizado no direito brasileiro por Wolkmer, qual seja, o pluralismo jurídico de tipo comunitário-participativo, pode ser afirmado da seguinte maneira:

[...] um pluralismo jurídico (designado comunitário-participativo) configurado através de espaços públicos abertos e compartilhados democraticamente, privilegiando a participação direta de sociabilidades excluídas e subalternas, capazes de instaurar novos direitos enquanto necessidades desejadas e possibilitando que o processo histórico de lutas se encaminhe por vontade e por manifestação autêntica das bases comunitárias. (WOLKMER, 2015, p. $82)$.

Assim, faz-se imperioso destacar as novas formas emancipatórias e contrahegemônicas de legitimação dos direitos humanos. Para o autor, essas formas precisam reordenar as relações tradicionais entre Estado e sociedade, entre o universalismo ético e o relativismo cultural, ou até mesmo entre as formas convencionais de legalidade e as 
experiências plurais não-formais de jurisdição (WOLKMER, 2006, p. 113-114).

Pontua que esse novo paradigma deve conter características participativas, considerando os novos sujeitos, bem como a descentralização, do centro para a periferia. Assim, um "novo" pluralismo jurídico, diferente dos demais, seria o ideal, pois, a partir dele poderia ser vislumbrada uma dinâmica interativa e flexível de um espaço público aberto, compartilhado e democrático entre todos os atores que compartilham o mesmo espaço-tempo (WOLKMER, 2015, p. 170-171).

Portanto, reivindica algo que difere do monismo jurídico, bandeira do direito na modernidade, o qual não admite a possibilidade de coexistência de vários sistemas normativos dentro no mesmo Estado-Nação. As características deixadas pelo modelo colonial, cujo desrespeito histórico pelo 'outro' levou a várias formas de marginalização, repercutindo na proibição de administrar a justiça de acordo com suas normas, valores e princípios, e, quando submetidos ao direito oficial, seus costumes e participação são desconsiderados (FAJARDO, 2008, p. 01).

Rompendo com o monismo jurídico, cita-se o caso boliviano, representado pela Sentença $\mathrm{n}^{\mathrm{o}}$ 1422/2012, do Tribunal Constitucional Plurinacional, demonstrando possibilidades outras na relação entre Estado e Sociedade, tal como o proposto pelo pluralismo jurídico comunitário-participativo.

No referido caso, tem-se um conflito no âmbito de uma comunidade indígena. A comunidade, em assembleia, deliberou pela expulsão do membro autor de um furto, junto de toda a sua família. De tal decisão, decorreu ação da família, sob alegação de violação a direitos humanos. O Tribunal Constitucional Plurinacional, no julgamento do caso, optou pela interpretação plural na solução do conflito.

Assim, o Tribunal apoiou-se em laudo técnico produzido por um importante órgão de apoio, a Unidade de Descolonização, composta por uma equipe interdisciplinar e que visita as comunidades indígenas envolvidas em conflitos submetidos à jurisdição constitucional. $\mathrm{O}$ laudo, analisando a comunidade onde se deflagrou o conflito, apresentou informações baseadas especialmente em aspectos antropológicos, onde ficou clara a existência pré-colonial da comunidade, com ascendência Quechua.

Entre as práticas ancestrais, incluíam-se meios próprios de solução de conflitos, de forma que a expulsão, de fato, era considerada uma espécie de sanção, entretanto, reservada somente a casos extremos. Assim, visando garantir o legítimo exercício da jurisdição indígena, sobre as bases do pluralismo jurídico, descolonização, interculturalidade e outros 
princípios vigentes na última Constituição boliviana, a sentença $\mathrm{n}^{\circ}$ 1422/2012, do Tribunal Constitucional Plurinacional, consagrou a enunciação de que a jurisdição indígena originária campesina, constitui na Bolívia, fonte direta e primária de direitos:

[...] o pluralismo jurídico, gera como efeito no modelo de Estado, a consagração de um pluralismo de fontes jurídicas, aspecto que implica na superação do Estado Monista; portanto, em reconhecimento a este aspecto, tem-se que a ordem jurídica imperante no Estado Plurinacional da Bolívia está conformada por dois elementos essenciais: 1) A Constituição como fonte primeira e direta de direito; 2) as normas e procedimentos das nações e povos indígenas originário campesinos, também como fonte direta de direito (BOLÍVIA, 2012).

Uma das consequências desta enunciação é o dever de interpretar os conflitos da jurisdição originária mediante novas técnicas, que respeitem a racionalidade própria das comunidades, que, em diversos aspectos se distingue da racionalidade colonizadora. Neste sentido, a inviolabilidade dos direitos fundamentais, constitucionalmente previstos, deve ser julgada sobre as bases da interculturalidade (FERRAZO; LIXA, 2017, p. 2648).

Dessa forma, a subversão do modelo ocidental de Estado e Direito se deu na Bolívia sobre as bases do pluralismo jurídico, visto que propõe um sistema de direitos fundado nos sujeitos coletivos e na inclusão de novas vozes, especialmente as comunidades indígenas (FERRAZO; LIXA, 2017, p. 2639-2640).

A conclusão neste caso, foi no sentido de revogar a decisão da comunidade pela expulsão do autor do furto e de sua família e tal decisão baseou-se na constatação de que a decisão afrontou o mínimo jurídico estabelecido na constituição, inclusive, interculturalmente interpretado. Também foi reputada pelo Tribunal, desproporcionalidade da medida, especialmente em razão de os efeitos da decisão ultrapassarem o autor do fato e alcançarem os membros de sua família, incluindo mulheres e crianças (FERRAZO; LIXA, 2017, p. 2649).

Diante do exposto, depreende-se que a noção contemporânea de direitos humanos pode ir muito além dos propósitos liberais dos cidadãos. Pelo contrário, essa noção objetiva alargar a sua concepção de humanidade e de dignidade humana para além do modelo padrão de sujeito racional moderno, revertendo os processos de vulnerabilização dos seres humanos e reforçando os princípios da dignidade humana e da não-discriminação (BRAGATTO, 2018, p. 54).

Entretanto, no caso brasileiro, ainda não se verifica a amplitude dessa noção. Conforme discorre Carlos Frederico Marés de Souza Filho (2012, p. 75-76), embora o 
respeito à diversidade cultural esteja reconhecido na Constituição de 1988, é possível dizer que existe uma lacuna quando se trata da efetiva proteção dos direitos dos povos originários. Isso porque, o Estado brasileiro, ainda muito assentado no paradigma liberal-individualista, não possui espaço para o coletivo, posto que o individualismo é tido como a nova fronteira da civilização, o novo marco da liberdade.

Assim, segundo o autor, resta à toda América Latina a criação de um novo modelo que seja tipicamente latino-americano (SOUZA FILHO, 2012, p. 193-196). A noção contemporânea de direitos humanos deve orientar os compromissos constitucionais, devendose rever a lógica do Estado a partir de outras perspectivas, rompendo paradigmas e, sobretudo, incorporando vozes outrora subalternizadas.

\section{CONCLUSÃO}

Diante do exposto, foi possível identificar que a questão dos direitos humanos relacionada a sua universalidade, seus fundamentos, bem como seus alcances e limites, especialmente em um contexto multicultural, possui diversas interpretações.

Embora cada entendimento possua suas especificidades, uma finalidade comum pode ser indicada, qual seja, a busca pela efetiva proteção dos direitos humanos. Para tanto, segundo Bobbio, o esforço deve ser concentrado em questões jurídicas e políticas, e não no fundamento filosófico dos direitos humanos. Barretto, por sua vez, vê como imprescindível o debate acerca dos fundamentos dos direitos humanos para garantir-lhes efetividade.

Independente da interpretação adotada, uma abordagem crítica acerca da utilização imperialista do discurso universal dos direitos humanos nos moldes individualista-liberal deve ser feita. Isso porque, não raras vezes, sob a égide dessa espécie de discurso, diversas violações a direitos humanos foram praticadas, especialmente quando envolvendo indivíduos que não se coadunam com a lógica da moderna e ocidental.

Tem-se como exemplo o caso dos indígenas na América Latina que, durante muito tempo, sequer foram considerados seres humanos e, portanto, sequer cogitou- se que possuíam dignidade humana. Embora no decorrer da história muitos direitos tenham sido assegurados a esses povos, ainda se opera uma lógica de colonialidade que subestima algumas culturas em relação a outras ditas civilizadas.

Dessa forma, necessária a proposta da interculturalidade, uma vez que permite a aceitação do diferente como uma oportunidade de enriquecimento e transformação de ambas 
as partes. Sendo assim, a universalização dos direitos humanos se torna possível sem que para isso signifique uma imposição hegemônica de uma cultura sobre a outra.

\section{REFERÊNCIAS}

BARRETTO, Vicente de Paula. Direitos humanos, democracia e globalização. In: STRECK, Lenio Luiz; BARRETO, Viente; CULLETON, Alfredo Santiago (Orgs.). 20 anos de Constituição: os direitos humanos entre a norma e a política. São Leopoldo: Oikos, 2009, p. 266.

BARRETTO, Vicente de Paula. O fetiche dos direitos humanos e outros temas. Rio de Janeiro: Lumen Juris, 2010.

BOBBIO, Norberto. A Era dos Direitos. Nova edição, Tradução: Carlos Nelson Coutinho. Rio de Janeiro, Ed.Elsevier, 2004. Disponível em: https://edisciplinas.usp.br/pluginfile.php/297730/mod_resource/content/0/norberto- bobbio-aera-dos-direitos.pdf. Acesso em 05 ago. 2019.

BOLÍVIA. Tribunal Constitucional Plurinacional. Sentença $\mathbf{n}^{\mathbf{0}}$ 1422/2012. Órgão Julgador: Sala Terceira. Relatora: Dra. Ligia Mónica Velásquez Castaños. Julgamento: 24/09/2012. Disponível em:http://www.stf.jus.br/repositorio/cms/portalStfInternacional/newsletterPortalI nternacionalDestaques/anexo/Resolucion_1422_2012_Tribunal_Constituciona 1_de_Bolivia.pdf. Acesso em 29 jul. 2019.

BRAGATO, Fernanda Frizzo. Sobre o Conceito de Minorias: Uma Análise sobre Racionalidade Moderna, Direitos Humanos e Não-discriminação. In: STRECK, Lenio Luiz; ROCHA, Leonel Severo; ENGELMANN, Wilson (Org.). Constituição, Sistemas Sociais e Hermenêutica: Anuário do Programa de Pós-Graduação em Direito da Unisinos. Mestrado e Doutorado: ${ }^{\circ}$ 14. São Leopoldo: Karywa, Unisinos, 2018.

BRAGATO, Fernanda Frizzo; BARRETTO, Vicente de Paulo; SILVEIRA FILHO, Alex Sandro da. A interculturalidade como possibilidade para a construção de uma visão de direitos humanos a partir das realidades plurais da América Latina. Revista da Faculdade de Direito UFPR, Curitiba, v. 62, n. 1, p. 33-59, jan./abr. 2017.

BRAGATO, Fernanda Frizzo. Pessoa humana e direitos humanos na Constituição Brasileira de 1988 a partir da perspectiva pós-colonial. 2009. 350 p. Tese (Doutorado em Direito) - Programa de Pós-Graduação em Direito, Universidade do Vale do Rio dos Sinos, São Leopoldo/RS, 2009.

CULLETON, Alfredo; BRAGATO, Fernanda Frizzo; FAJARDO, Sinara Porto. Curso de direitos humanos. São Leopoldo: Unisinos, 2009. 
FAJARDO, Raquel Yrigoyen. Rondas campesinas y desafios del pluralismo legal en el Perú. 2008. Disponível em: http://www.jus.unitn.it/cardozo/Review/2008/Fajardo.pdf. Acesso em: 02 ago. 2019.

FERRAZO, Débora; LIXA, Ivone Fernandes Morcilo. Pluralismo jurídico e interpretação plural na jurisdição constitucional boliviana. Revista Direito e Práxis, Rio de Janerio, Vol. 08, N. 04, 2017, p. 2629-2657.

LUCAS, Douglas Cesar. O problema da universalidade dos direitos humanos e o relativismo de sua efetivação histórica. Revista Novos Estudos Jurídicos. Itajaí, v. 14, n. 3, p. 124-145, dez. 2009. Disponível em: http://vlex.com/vid/universalidade- relativismo --efetiva74589595. Acesso em 05 ago. 2019.

MAZZA, Willame Parente; COSTA; Marcelo Cacinotti. Multiculturalismo: entre o Universalismo e o Relativismo dos Direitos Humanos. Revista Jurídica da Presidência. Brasília v. 18 n. 115, jun./set. 2016, p. 387-408.

RAMOS, André de Carvalho. Teoria geral dos direitos humanos na ordem internacional. Rio de Janeiro: Renovar, 2005.

SANTOS, Boaventura de Sousa. Uma concepção multicultural de direitos humanos. Revista Crítica de Ciências Sociais. No 48, junho, 1997.

SOUZA FILHO, Carlos Frederico Marés. O renascer dos povos indígenas para o direito. Imprenta: Curitiba, Juruá, 2010.

WOLKMER, Antônio Carlos. Direitos Humanos: novas dimensões e novas fundamentações. Direito em Debate. Ano X, no 16/17, jan./jun. 2002.

WOLKMER, Antônio Carlos. Pluralismo jurídico: fundamentos de uma nova cultura do direito. 4a Ed. São Paulo: Saraiva, 2015. Disponível em: http://www.forumjustica.com.br/wp-content/uploads/2013/02/Antonio-Carlos- WolkmerPluralismo-juridico.pdf\&gt. Acesso em: 02 jul. 2019. 